\title{
Iván Rivera en el recuerdo
}

\author{
José A. Oscátegui A. \\ A person who will listen and not condemn \\ Someone on whom you can depend \\ A Friend, por Gillian Jones (2008)
}

Hace bastante tiempo que conocí a Iván. Eran los primeros años de la década de 1980 y yo, un par de años antes, después de estudiar sociología, había decidido estudiar economía. Conocí a Iván como mi profesor de Macroeconomía.

Él nos enseñó lo que se acostumbraba enseñar en un primer curso de Macroeconomía en esa época; me refiero al modelo keynesiano en su versión de cruz keynesiana y en la versión IS-LM. Pero poco tiempo después, cuando en cursos posteriores él empezó a usar un libro de Robert Barro, comencé a descubrir que el curso que me enseño no fue el que él, realmente, quería dictar. El curso que llevé con Iván no habría sido tan significativo si él no hubiera poseído ese fuego polémico que lo caracterizó, que despertaba entusiasmos y rechazos, así como también hacía aflorar afiliaciones en los alumnos, logrando que las clases fueran acompañadas con pequeños debates entre los alumnos y el profesor.

En todo el tiempo que lo conocí pude reconocer tres características que pueden definirlo. Él tuvo siempre una gran honestidad intelectual y de vida; también fue abierto, intelectual y prácticamente, a otras posturas académicas y políticas, y tuvo un discurso y una vida que fueron admirablemente consistentes.

Cuando conocí a Iván yo poseía una visión de izquierda que ahora considero primitiva y equivocada. Como muchos coetáneos, consideraba que el mercado era un obstáculo para el desarrollo y la justicia social en nuestro país. En ese entonces, en estos temas, Iván estaba en la orilla del frente de donde yo me encontraba.

Habiendo terminado exitosamente sus estudios de doctorado en la Universidad de Chicago, había tenido como profesor a Milton Friedman, y sintiéndose destinado a hacer lo necesario para mejorar a su patria, él se sentía obligado a ser no solo economista sino también algo de predicador. Su objetivo era conseguir que la idea del mercado,

\footnotetext{
* Departamento de Economía de la Pontificia Universidad Católica del Perú.
} 
como vía para la solución de los problemas del país, se encarnara en la población. Poco tiempo después, Iván es nombrado Ministro de Industria en el gobierno de F. Belaúnde y, un poco después de terminadas sus funciones, es contratado por el Banco Mundial y viaja a residir a Washington ${ }^{1}$.

Hay que recordar que en los años de 1980 la sociedad peruana estaba, políticamente, bastante polarizada y el discurso alternativo desde la izquierda política, sostenía que la solución para el país solo podía venir de la eliminación del mercado. Los matices de diferencia dentro de este último discurso se fueron perdiendo y, hacia el fin de la década, la propuesta y la acción política de Sendero Luminoso había hegemonizado el discurso de la izquierda ${ }^{2}$. La derecha política no era menos radical, sino solo con signo contrario, y teniendo en sus manos los mecanismos del poder, actuó con similar brutalidad, generando, entre ambas fuerzas, las más de 70000 víctimas que señala la Comisión de la Verdad y Reconciliación.

La década de 1980 generó también un discurso alternativo, que después fue señalado como de izquierda. Sin embargo, este esfuerzo por generar un discurso económico diferente desde un país subdesarrollado, se basó, más que en el marxismo (que era el pensamiento de izquierda de la época), en esfuerzos por comprender y aplicar la teoría keynesiana, que también estaba evolucionando ${ }^{3}$. Debe señalarse, por ejemplo, el esfuerzo que se hizo por incluir en el análisis, el carácter monopolista u oligopolista de la economía en general, y peruana en particular. Este tema fue uno de los principales rasgos, en esos años, de los trabajos realizados a nivel internacional para actualizar el discurso keynesiano ${ }^{4}$.

En la base del análisis heterodoxo estuvo la consideración de que el mercado peruano tenía un carácter oligopólico y por ello reducido, en el que las empresas funcionaban con exceso de capacidad y costos elevados. Este régimen, junto con las devaluaciones de la moneda, que ocurrían desde fines de la década de 1970, y con la nueva estructura de la economía que surgió durante el período de gobierno de Velasco Alvarado, eran los generadores de inflación.

Una microeconomía particular, sin mayor respaldo de investigación empírica, llevó a los teóricos heterodoxos a sostener que la curva de oferta agregada de la economía peruana tenía, en la mayor parte de su extensión, pendiente negativa en la parte relevante, era plana en la siguiente sección, y tenía pendiente positiva solo en un pequeño tramo final. Por esto, se afirma en El Perú heterodoxo, las devaluaciones generaban de

\footnotetext{
1 Mientras estuvo a cargo del Ministerio de Industria, Iván siguió siendo docente activo de nuestro Departamento de Economía, manteniendo su horario de clases.

2 La mayor diferencia al interior de esta fuerza estaba en si era necesaria o no el uso de la violencia.

3 Aquí hacemos una rápida revisión de algunos capítulos del libro El Perú heterodoxo (Carbonetto et al., 1987).

4 Refiriéndose a los modelos de la época, recientes nuevo keynesianos, Ball, Mankiw y Romer (1988) dicen: «Recent progress is largely a result of two innovations in modeling: the introduction of imperfect competition and greater emphasis on price rather than wage rigidities».
} 
parte de los trabajadores exigencias de incremento del salario nominal, lo que, junto con el aumento de la tasa de interés, reducía el margen de ganancia, por lo que la respuesta empresarial era elevar los precios y/o aumentar el nivel de mark-up. Así, la curva de oferta se desplazaba hacia arriba con el resultado de tener un equilibrio con menor producción y mayores precios. La inflación era impulsada por los costos. Pero, detrás de ese proceso de aumento de los precios, también había una pugna social entre trabajadores y empresarios, cada uno en busca de mejorar su situación.

\section{LA EXPLICACIÓN «HETERODOXA» DE LA INFLACIÓN}

A la explicación, digamos «ortodoxa», de la inflación como resultado de un exceso de demanda generado por el déficit fiscal, la explicación «heterodoxa» sostenía que las cosas eran al revés, tal como está escrito en el libro El Perú heterodoxo, con trabajos de Daniel Carbonetto, Oscar Dancourt, César Ferrari, Gustavo Saberbein y otros.

Durante el período que va de 1968 hasta 1980 la economía y sociedad peruanas experimentaron cambios importantes de modo que «en la economía peruana, la intervención del Estado no solo se traduce en la determinación de la demanda agregada nominal vía gastos e impuestos... El rol del Estado en el sistema de precios, en la determinación del nivel de precios y de la estructura de precios relativos, es también muy importante a través de los precios controlados» (Carbonetto et al., 1987). Como consecuencia de ello, sostenían los «heterodoxos», los esfuerzos por cerrar la brecha fiscal aumentaban la inflación en una espiral continua. El gobierno aumentaba el precio de los servicios (agua, electricidad, telefonía) que estaban controlados, reducía los subsidios que otorgaba al precio de varios productos (alimentos, entre ellos). Así, los «intentos de reducir el déficit fiscal elevando los precios controlados (han)... terminado, paradójicamente, convirtiéndose en una de las principales causas de la inflación peruana». Iván no podía estar de acuerdo con este análisis, por el contrario, se ubicó en el extremo opuesto.

Los años del período fujimorista estuvieron signados por la desaparición de la actividad política Mientras el «senderismo» era diezmado militar y políticamente, la izquierda fue demonizada, desorganizada, perseguida y acusada de ser «senderista», y la derecha, desorganizadamente, pero bajo la dirección de Fujimori y Montesinos, se hizo cargo del poder. Por otro lado, en Perú, luego de la hiperinflación y el ascenso de Alberto Fujimori al poder, las propuestas económicas heterodoxas de raíz keynesiana, quedaron desprestigiadas. Entonces, empezó la época en la que dominó, aunque solo por alrededor de una década, la idea de que el mercado sin regulación era la solución para los problemas de pobreza e integración en el país. Periodistas audaces, con solo hablar de Oferta y Demanda, parecían poseer el conocimiento necesario para explicar los graves problemas del país. Aunque estoy seguro de que Iván lo entendía con mucha mayor profundidad, pues él, al igual que su maestro Friedman, apreciaba críticamente el trabajo de Keynes. Debe haber sentido sin embargo, que este discurso, aunque incorrecto, era más cercano al suyo. 


\section{LA INQUIETUD INTELECTUAL DE IVÁN}

Durante los primeros años del período fujimorista Iván trabajó en el Ministerio de Economía.

Entre tanto, durante los decenios de 1970 y 1980, en Estados Unidos fue desarrollándose la crítica contra el keynesianismo 5 . Esta provenía de esa nueva escuela, en gran medida continuadora del monetarismo de Milton Friedman, conocida como las Expectativas Racionales (DeVroey, 2016). Pese al gran respeto que Lucas mostró por el trabajo de Keynes, las versiones de este nuevo enfoque que llegaron a nuestro país fueron totalmente negativas y equivocadas, pues muchos entendieron que la «nueva verdad» implicaba no solo la desaparición de la teoría keynesiana, sino también de la política económica como tal: el modelo reemplazaría a la realidad, pues esta ya estaba incorporada en el modelo. La política económica sería inefectiva, pues los agentes económicos anticiparían el efecto de ellas y modificarían su comportamiento hasta anular dichos efectos.

No me consta que Iván se haya entusiasmado con esta propuesta, sin embargo, la sentía más cercana que cualquier propuesta de la vereda de enfrente. Durante la década de 1990, pese al trabajo que tenía en el Banco Mundial, su curiosidad intelectual lo llevó a interesarse por esos desarrollos novedosos, aunque no profundizó en ellos.

Mi mayor cercanía con Iván ocurrió durante esa década, pero más aún en la de 2000. Iván ya se había retirado del Banco Mundial, pero, como le ocurría siempre, sentía la necesidad de ser docente. En su condición de profesor principal del Departamento de Economía de la PUCP, solicitó dictar un semestre al año y pudo hacerlo. Así fue que comenzamos a departir más a menudo. Nos veíamos en el Departamento de Economía y también, eventualmente, fuera de la Universidad, en casa de amigos comunes, y pensamos en dos proyectos que no llegamos a concretar.

El primero, era hacer un trabajo sobre el mercado laboral peruano, pero él sabía y me lo decía, que iba a ser difícil que lo hiciéramos, pues teníamos enfoques bastante diferentes del tema. El segundo, sí hubiéramos podido llevarlo a cabo. Pese a que recién había terminado su libro Principios de Macroeconomía, él no estaba plenamente satisfecho con él, ya que lo consideraba demasiado keynesiano y era consciente de que carecía de un enfoque intertemporal y dinámico. Las últimas semanas antes de su intempestiva muerte, nos pusimos de acuerdo telefónicamente en hacer un texto de macroeconomía, que fuera teórica y metodológicamente más actual. Esta tarea está pendiente.

5 Como sostiene Woodford (1999), la macroeconomía ha sido siempre controvertida y las discusiones sobre su evolución durante el siglo XX hacen frecuentes alusiones a revoluciones y contrarrevoluciones. La década de los años 80 del siglo pasado corresponde a la declinación de la Revolución Keynesiana y el surgimiento de la Revolución Monetarista que sería seguida por la Revolución de las Expectativas Racionales de los Nuevos Clásicos. 


\section{UN BALANCE}

Mi mayor deuda con Iván es, primero, por lo que me enseñó cuando fui su estudiante, pero últimamente por su integridad, su amistad y su apoyo intelectual. Aunque no era infrecuente que sus fuertes convicciones generaran desacuerdos también fuertes con algunos de sus interlocutores y también conmigo, puedo decir que él sabía ser amigo. Siempre supe que podía enviarle un texto y que él lo comentaría, aún si este era solo un par de ideas generales y desordenadas, y siempre me alentaba. Él era, intrínsecamente, una muy buena persona.

Entre su legado están sus alumnos, pero también sus dos libros recientes sobre Teoría Microeconómica y Teoría Macroeconómica con lo que él mismo llamó «un enfoque de sentido común». Su muerte fue una sorpresa para mí; sabía que él llegaría a Lima el 4 de marzo, es decir, solo 15 o 20 días después de su inesperada partida. Aunque tenía algunos problemas de salud, había aprendido a controlarlos, y sus amigos nos habíamos acostumbrado a verlo viviendo como si esos problemas no existieran.

Haciendo un balance, creo que se puede constatar que el Perú ha cambiado y que la ciencia económica también lo ha hecho. El país está con posiciones políticas menos extremas, y creo que la economía también. El pensamiento de Iván convergió, pero también el de los que discrepaban con él convergió hacía el suyo, tanto así que en 2005 surge en nuestro país una fuerza política con la propuesta de La Gran Transformación, que sostiene que el problema del país es la falta de mercados, y que el mercado no es antagónico, ni al bienestar ni a la igualdad social. En la actualidad, aunque la derecha sigue siendo rentista, la izquierda, en su mayoría, acepta que una economía de mercado moderna es necesaria para el desarrollo.

Por otro lado, en la década de 1980 o 1990 hubiera sido impensable que uno de los economistas más reconocidos, como es el caso de Olivier Blanchard (2017), refiriéndose al aporte tal vez más representativo de Milton Friedman, escribiera:

While the natural rate hypothesis was controversial at the time, it quickly became widely accepted, and has been the dominant paradigm in macroeconomics ever since. It is embodied in the thinking and the models used by central banks, and it is the basis of the inflation targeting framework used by most central banks today (p. 3).

Por el lado personal puedo entender y sentir mejor el poema de John Donne ${ }^{6}$. Nadie es una isla en sí mismo y todos somos parte del continente. La muerte de cualquiera nos disminuye, pues somos parte de ese continente que es la humanidad. Perdemos más cuánto más cercanos seamos al que parte. Las campanas no doblan por los que se van, sino por los que se quedan, nosotros somos los que perdemos. Por esto no tengo duda que, tras la muerte de Iván, las campanas doblan por nosotros y por mí en particular.

\footnotetext{
6 Meditation XVII-Nunc Lento Sonitu Dicunt, Morieris (No Man is an Island).
} 


\section{REFERENCIAS}

Ball, Laurence, N. Gregory Mankiw, David H. Romer (1988). The New Keynesian Economics and the Output-Inflation Trade Off. Brookings Papers on Economic Activity 1.

Blanchard, Olivier J. (2017). Should we get rid of the Natural Rate Hypothesis? NBER WP\#24057. https://doi.org/10.3386/w24057

Carbonetto, Daniel, M. Inés C. de Cabellos, Oscar Dancourt, César Ferrari, Daniel Martinez, Jaime Mezzera, Gustavo Saberbein, Javier Tantaleán y Pierre Vigier (1987). El Perú heterodoxo: un modelo económico. Lima: Instituto Nacional de Planificación.

De Vroey, Michel (2016). A History of Macroeconomics from Keynes to Lucas and Beyond. Nueva York: Cambridge University Press. https://doi.org/10.1017/cbo9780511843617

Donne, John (1624). Meditation XVII-Nunc Lento Sonitu Dicunt, Morieris. En Devotions Upon Emergent Occasions [No Man is an Island].

Jones, Gillian E. (2008). For A Friend Who Helped Me. Recuperado de https://www. familyfriendpoems.com/poem/a-friend

Woodford, Michael (1999), Revolution and Evolution in XX Century Macroeconomics. Paper presented at the Conference Frontiers of the Mind in the Twenty-First Century, U.S. Library of Congress, Washington, DC, June 1999. http://www.columbia.edu/ mw2230/ macro20C.pdf

Documento recibido el 12 de marzo de 2018 y aprobado el 20 de julio de 2018 